Planta (Berl.) 115, 59-72 (1973)

(C) by Springer-Verlag 1973

\title{
Respiration and Oxygen Transport in Soybean Nodules
}

\author{
J. D. Tjepkema and C. S. Yocum* \\ Department of Botany, University of Michigan, Ann Arbor, Michigan 48104, USA
}

Received May 21 / September 27, 1973

\begin{abstract}
Summary. The respiration rate of individual soybean (Glycine max Merr.) nodules was measured as a function of $\mathrm{pO}_{2}$ and temperature. At $23^{\circ}$, as the $\mathrm{pO}_{2}$ was increased from 0.1 to $0.9 \mathrm{~atm}$, there was a linear increase in respiration rate. At $13^{\circ}$, similar results were obtained, except that there was an abrupt saturation of respiration at approximately $0.5 \mathrm{~atm} \mathrm{pO}_{2}$. When measurements were made on the same nodule, the rate of increase in respiration with $\mathrm{pO}_{2}$ was the same at $13^{\circ}$ and $23^{\circ}$. Additional results were that $5 \% \mathrm{CO}$ in the gas phase had no effect on respiration, except for a small decrease in the $\mathrm{pO}_{2}$ at which respiration became saturated. Also, nodules still attached to the soybean root displayed the same respiratory behavior as detached nodules. A model for oxygen transport in the nodule is presented which explains these results quantitatively. The essence of the model is that the respiration rate of the central tissue of the nodule is almost entirely determined by the rate of oxygen diffusion to the respiratory enzymes. Evidence is given that the nodule cortex is the site of almost all of the resistance to oxygen diffusion within the nodule.
\end{abstract}

\section{Introduction}

Little information is available about oxygen transport in the nodules of soybeans and of other legumes. This topic is of substantial interest since oxygen partial pressure strongly affects the rate of nitrogen fixation and acetylene reduction in soybean nodules (Bergersen, 1962a, 1970; Mague and Burris, 1972). Also, examination of oxygen transport in soybean nodules might give information about the possible role of leghemoglobin in oxygen transport.

Bergersen (1962a) measured the respiration rate of soybean nodules as a function of $\mathrm{pO}_{2}$ and found a unique two-step curve. We have also made such measurements, and have obtained somewhat different results. From these results and from calculations based on nodule anatomy, we have developed a theory of nodule respiration which differs from that of Bergersen and which helps to explain the role that leghemoglobin may play in oxygen transport in the nodule. Further details of this work are available in Tjepkema (1971).

* To whom reprint requests should be sent. 


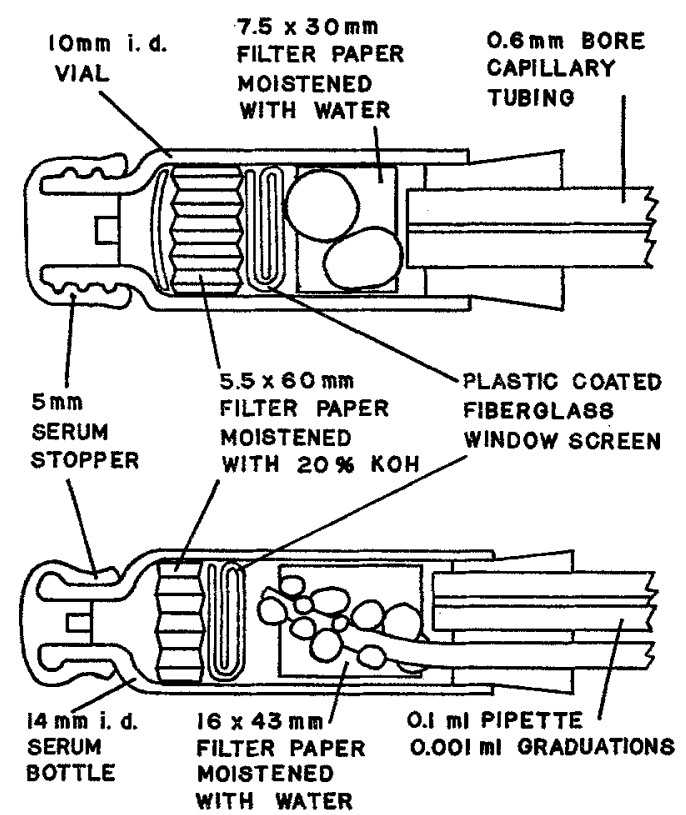

Fig. 1. Construction of volumeters

\section{Materials and Methods}

Growth of Soybeans. Soybeans, Glycine max Merr. cv. Chippewa, were grown in a greenhouse in pots filled with vermiculite and were inoculated with a commercial preparation of rhizobia (W. R. Grace \& Co., Princeton, Ill., USA). The plants were watered 3 times a week with a nitrogen-free mineral nutrient solution. In the winter, supplementary light was provided by a bank of twelve fluorescent lamps (8 ft, $200 \mathrm{~W}$, "cool-white", from various manufacturers) and six 100-W ineandescent lamps. The photoperiod was $13 \mathrm{~h}$. Nodales were harvested from the plants at approximately the time of flowering.

Volumetry for Detached Nodules. Volumetry was by a more sensitive version of the method of Thimann et al. (1954). The volumeters were made as shown in Fig. 1. The vessels were lined with moist filter paper to keep the humidity high. Humidity may affect respiration rate, since it strongly affects acetylene reduction rate (Sprent, 1969). The capillary bores were periodically cleaned with chromicsulfuric aeid solution (Kirk, 1950). The kerosene used to indicate volume was purified by collecting the fraction boiling at $200-230^{\circ}$ and storing it over $\mathrm{KOH}$ pellets (Kirk, 1950). The vessels were placed vertically in a well-stirred water bath, the temperature of which was regulated by a mercury thermostat. A thermobarometer, prepared identically to the experimental vessels was used, but the corrections were always quite small. Air temperature was kept at $\pm 2^{\circ}$ of bath temperature. Gas mixtures were made in disposable $30 \mathrm{~cm}^{3}$ plastic syringes, using either air and oxygen or air and nitrogen. A small amount of water was kept in the syringe to humidify the gas. After the mixtures were made, the syringes were kept in the water bath until used. 
To begin an experiment, a nodule was detached from the plant, rinsed quickly in running tap water, then distilled water, and blotted. After placing the nodule in the volumeter, $30 \mathrm{~min}$ were allowed for temperature equilibration. Five minutes before the end of this period, $20-25 \mathrm{~cm}^{3}$ of 90 or $100 \%$ oxygen were flushed through the vessel. The thermobarometer was not usually flushed with gas, air being kept in it throughout the experiment. But when the thermobarometer was flushed, there was little or no difference in the results. A small drop of kerosene was introduced by pushing down on the volumeter and then releasing the pressure, which sucked the kerosene into the capillary. Readings of the position of the kerosene were taken every minute for a minimum of $6 \mathrm{~min}$. The volumeter was then removed from the water bath, the gas mixture was rapidly changed, and the first reading of the new mixture was taken 1 min after the last reading of the previous mixture. This first reading, and often the second, was discarded since it was usually higher or lower than the following readings, due to temperature changes during the gassing procedure. The order in which the gas mixtures were changed was always from high $\mathrm{pO}_{2}$ to low $\mathrm{pO}_{2}$ and usually two sets of measurements for each experimental treatment were made, each going from high $\mathrm{pO}_{2}$ to low $\mathrm{pO}_{2}$. When the bath temperature was changed, thirty minutes were allowed for temperature equilibration. At the end of an experiment the nodules were weighed, and the mean diameter was calculated from the fresh weight, assuming a nodule density of 1.0.

Volumetry for Attached Nodules. Volumetry was the same as for detached nodules, except for the changes noted below. The gas space was about $5 \mathrm{~cm}^{3}$ and about $25 \mathrm{~cm}^{3}$ of gas were flushed through when the gas mixture was changed. If there were ideal mixing, calculations show that this would remove $99 \%$ of the original gas. Several minutes were required to change the gas and allow for temperature equilibration. A soybean plant was prepared for measurement by cutting off the leaf blades to prevent water loss, and trimming away all roots except for a short section of the primary root where about one-third of the total number of nodules were attached. The plant was then inserted into a hole provided in the volumeter stopper, using a split made in the side of the stopper. Silicone grease was used to improve the seal between the stopper and the stem. Since there was a large air cavity at the center of this part of the stem, it is unlikely that the silicone grease affected gas transport through the stem. Readings in each gas mixture took from six to fifteen minutes, the longer readings being required when the kerosene tended to stick in the pipette bore.

\section{Results}

Fig. 2 shows the respiration of a single nodule as a function of $\mathrm{pO}_{2}$ at 13 and $23^{\circ}$. Two sets of measurements were taken at $13^{\circ}$, and then two sets at $23^{\circ}$. At $13^{\circ}$, respiration becomes oxygen-saturated at approximately $0.5 \mathrm{~atm} \mathrm{pO}_{2}$, while at $23^{\circ}$ there is no indication of saturation, even at $0.9 \mathrm{~atm} \mathrm{pO}_{2}$. All measurements were made on the same nodule, with $5 \mathrm{~h}$ elapsing between the first and last measurements. This set of measurements is somewhat unusual in that there was sometimes a more noticeable decrease in respiration rate between the 1 st and 2 nd sets of measurements at $23^{\circ}$. There was also less experimental error than usual. 


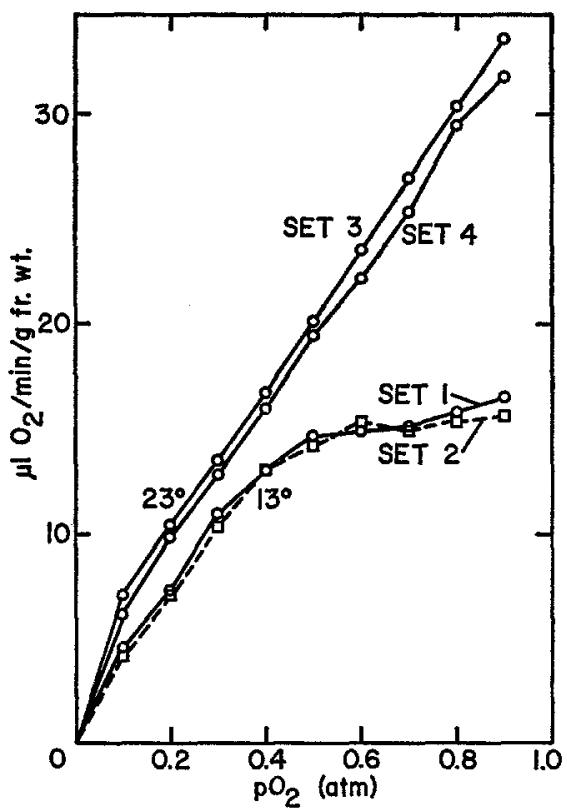

Fig. 2. Effect of temperature on nodule respiration. Plant age, 40 days; number of nodules, 1 ; mean nodule diameter, $6.4 \mathrm{~mm}$

We often observed a sharp elbow ${ }^{1}$ in the respiration curve at the point of oxygen saturation. Such a result is shown in Fig. 3. The reason why such a sharp elbow was not always observed may have been due to error in volumetry and gas mixing, failure to use a $\mathrm{pO}_{2}$ which was exactly at the point where the elbow occurred, and the possibility that some nodules, such as the one in Fig. 2, have a somewhat different behavior at this point.

The nodules were washed in all experiments except that of Fig. 4. This was done to remove small bits of vermiculite clinging to the nodules. For the experiment of Fig. 4, the plants used were not watered from the top of the pot for twenty two hours before the experiment was done. After detaching the nodule, the larger pieces of vermiculite were carefully removed with a flexible splinter of wood, and the first two sets of measurements were made. The 3rd and 4th sets of measurements were made after the nodule was removed from the volumeter, washed in tap and distilled water, blotted, and then returned to the volumeter. The respiration was very similar before and after washing the nodule. Above $0.5 \mathrm{~atm} \mathrm{pO}_{2}$, there was a decrease in respiration rate between the 1 st and 2nd sets of measurements. To prevent the possibility of further 1 The term "elbow" is used because there is apparently no formal mathematical term for this behavior. 


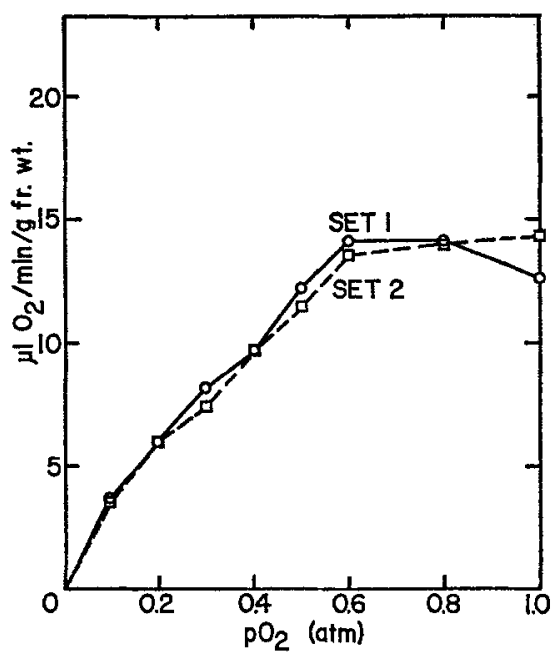

Fig. 3. Break in respiration curve at the point of oxygen saturation. Temperature, $13^{\circ}$; plant age, 53 days; number of nodules, 1 ; mean nodule diameter, $6.8 \mathrm{~mm}$

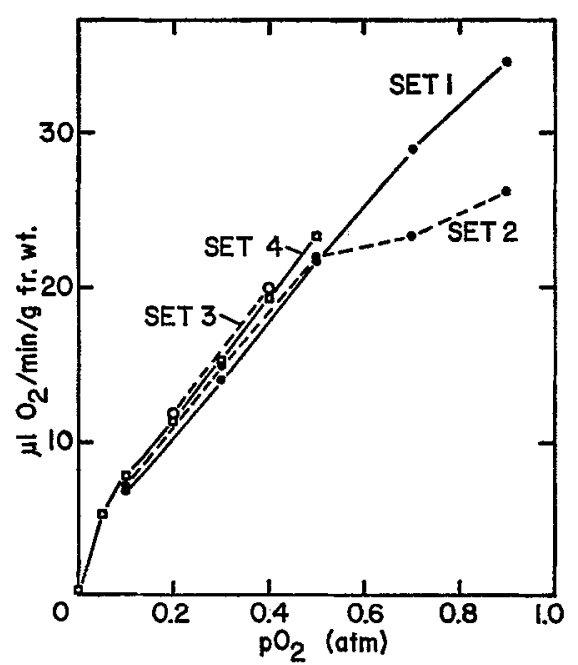

Fig. 4. Effect of washing on nodule respiration. Sets 1 and 2 were taken before washing, and 3 and 4 afterwards. Temperature, $23^{\circ}$; plant age 39 days; number of nodules, 1 ; mean nodule diameter, $5.9 \mathrm{~mm}$

decreases, no measurements above 0.5 atm $\mathrm{pO}_{2}$ were made in the third and fourth sets of measurements. Note that in the 4th set of measurements, the respiration rate at 0.05 and 0.00 atm $\mathrm{pO}_{2}$ was measured. The very small rate at $0.00 \mathrm{~atm}$ was probably due to a small oxygen contamination. 


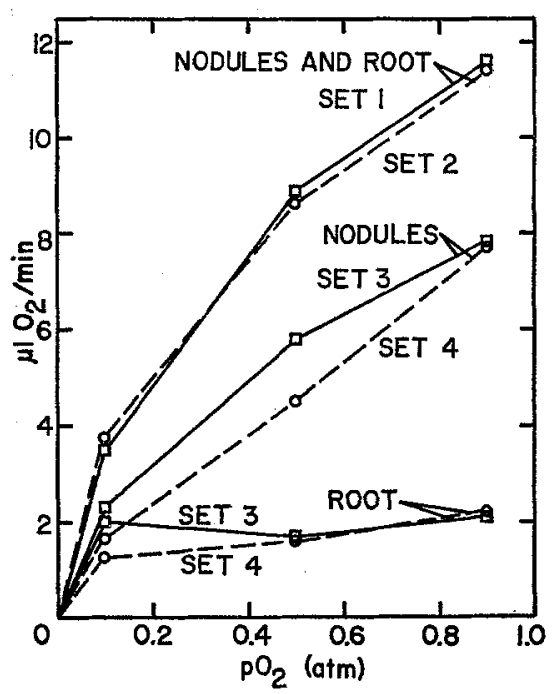

Fig. 5. Respiration of attached versus detached nodules. Sets 1 and 2 were taken before the nodules were detached, and 3 and 4 afterwards. Temperature, $23^{\circ}$; plant age 45 days; number of nodules, 15 ; mean nodule diameter, $3.8 \mathrm{~mm}$; root weight, $0.14 \mathrm{~g}$, nodule weight, $0.43 \mathrm{~g}$

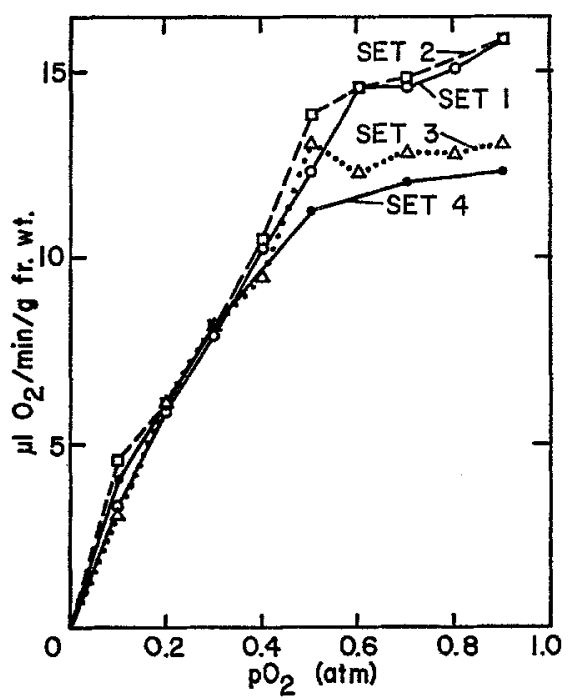

Fig. 6. Effect of $0.05 \mathrm{~atm} C O$ on respiration. Sets 1 and 2 were taken without $\mathrm{CO}$, and sets 3 and 4 were taken with $0.05 \mathrm{~atm} \mathrm{CO}$. Temperature, $15^{\circ}$; plant age, 52 days; number of nodules, 1 ; mean nodule diameter, $6.2 \mathrm{~mm}$ 
Fig. 5 shows the respiration of nodules and the portion of the root they are attached to before and after separation from each other. The respiration of the root is oxygen saturated at $0.1 \mathrm{~atm} \mathrm{pO}_{2}$, the lowest value measured. The respiration of the separated nodules or of the nodules and root attached together is similar to that observed in Fig. 2 for a single detached nodule.

In Fig. 6, the objective was to show the effect of binding leghemoglobin to $\mathrm{CO}$ so that it could not participate in oxygen transport. We used a pCO of $0.05 \mathrm{~atm}$, which should be sufficient to cause most of the leghemoglobin to be complexed with $\mathrm{CO}$, even at $0.9 \mathrm{~atm}$ external $\mathrm{pO}_{2}$. The experimental results are shown in Fig. 6. Carbon monoxide had no measurable effect on respiration, except to lower the $\mathrm{pO}_{2}$ at which respiration became oxygen saturated. The temperature of $15^{\circ}$ was used since at higher temperatures, oxygen saturation of respiration would not have been observed. Our results are somewhat different from those of Smith (1949), who found that 0.05 or 0.005 atm pCO usually caused a small stimulation of nodule respiration, measured at $0.20 \mathrm{~atm}$ $\mathrm{pO}_{2}$. Our experimental error may have been too large to detect such a stimulation.

\section{Discussion \\ Validity of the Measurements}

In this section we will consider two sources of experimental error that could have substantially affected our results. Specifically, washing the nodules before measurements might have caused water to be absorbed by the intercellular air spaces of the nodule cortex. If such spaces exist, this could possibly have caused the large resistance to oxygen diffusion that our results indicate. However, in the results of Fig. 4, washing the nodules had no significant effect on their respiration rate. Similar results have been reported by Mague and Burris (1972), who found that a brief washing did not alter the acetylene reduction rate of nodules.

A second possible error might have occurred if the nodule normally receives part of its oxygen via intercellular air spaces in the soybean root. But Sprent (1972) has concluded that there is no significant transport of oxygen from soybean shoots to the roots. Our results, shown in Fig. 5, support this conclusion. The respiration of attached nodules was very similar to that of detached nodules. Bond (1941) has also concluded that attached and detached nodules have about the same respiration rates.

\section{General Theory of Nodule Respiration}

We suggest the following explanation for the unusual shape of the plot of soybean nodule respiration versus $\mathrm{pO}_{2}$. We propose that the 5 Planta (BerI.), Vol. 115 
respiration of the central tissue of the nodule is almost entirely diffusion limited, due to the high resistance to oxygen diffusion through the nodule cortex. We also propose that the respiration of the cortex comprises a substantial fraction of the total nodule respiration rate at low $\mathrm{pO}_{2}$ values, with the cortex respiration becoming oxygen saturated at about $0.2 \mathrm{~atm} \mathrm{pO}_{2}$. A similar explanation of nodule respiration was proposed by Bergersen (1962a), with the chief difference being in his proposal that the membrane envelopes enclosing the bacteroids are the source of the high resistance to oxygen diffusion.

\section{Linearity and Elbow in Nodule Respiration Curves}

In this part of the discussion we will consider the explanation for the linear increase of nodule respiration with $\mathrm{pO}_{2}$, as observed in sets 3 and 4 of Fig. 2, at $\mathrm{pO}_{2}$ values above $0.1 \mathrm{~atm}$. We will also consider the sharp elbow in the respiration curve at the point of oxygen saturation of respiration, as shown in Fig. 3.

A linear increase in rate versus gas partial pressure, with a sharp elbow at saturation, has also been reported for photosynthesis rate versus $\mathrm{pCO}_{2}$ in water plants (Blackman and Smith, 1911). It appears that both this result and our own are explained by a model for photosynthesis developed by Lommen et al. (1971). Under certain conditions, for example those of Fig. 5 of their paper, with a " $\mathrm{K}$ " value of $0.01 \mathrm{nmol}$ $\mathrm{cm}^{-3}$, this model predicts the type of curve that we have experimentally observed.

The model of Lommen et al. is a mathematical description of photosynthesis rate versus $\mathrm{pCO}_{2}$, taking into consideration both the resistance to oxygen diffusion from the external atmosphere to the sites of $\mathrm{CO}_{2}$ fixation and a Michaelis-Menten equation for fixation of $\mathrm{CO}_{2}$ by the chloroplast enzymes. The conditions giving a linear rate increase versus $\mathrm{pCO}_{2}$, with a sharp elbow at the point of $\mathrm{CO}_{2}$ saturation, are a high value for diffusion resistance between the atmosphere and chloroplasts, and a high affinity for $\mathrm{CO}_{2}$ by the $\mathrm{CO}_{2}$-fixing enzymes. Under these conditions, the rate of photosynthesis is almost entirely limited by the rate of $\mathrm{CO}_{2}$ diffusion to the chloroplasts. Also note that this model assumes that the resistance between the external atmosphere and the enzyme sites is the same for all enzyme sites.

Let us now apply the model of Lommen et al. to the soybean nodule, where we are concerned with respiration instead of photosynthesis and $\mathrm{pO}_{2}$ instead of $\mathrm{pCO}_{2}$. The conditions under which the model will predict a linear increase in respiration rate as $\mathrm{pO}_{2}$ is increased are that the respiratory enzymes of the nodule have a high oxygen affinity, that the resistance to oxygen diffusion to the enzymes is high, and that the diffusion resistance is about the same for all enzyme sites. 
First let us consider the oxygen affinity of the respiratory enzymes. We will be concerned only with the respiration of the central tissue of the nodule in this section, since the respiration of the outer tissue appears to be associated with the initial, low $\mathrm{pO}_{2}$ part of the respiration curve. A large fraction of the total nodule respiration is probably due to the bacteroids, and these bacteroids are localized in the central tissue (Bergersen, 1962a). The bacteroids do indeed appear to have a high oxygen affinity, as is required for the model. Bergersen (1962 a) found that the respiration of the bacteroids was half-saturated at $1 \times 10^{-2} \mathrm{~atm}$ $\mathrm{pO}_{2}$, while Tjepkema (1971) found a value of about $2 \times 10^{-5} \mathrm{~atm} \mathrm{pO}_{2}$. The latter value may have been lower because the $\mathrm{pO}_{2}$ was measured within the bacteroid suspension, rather than in the gas phase above it.

Next we will consider the evidence that the resistance to oxygen diffusion to the respiratory sites is high. Good evidence for a large diffusion resistance comes from spectrophotometric evidence that the internal $\mathrm{pO}_{2}$ of nodules is very low (Appleby, 1969; Bergersen, $1962 \mathrm{~b}$; Tjepkema, 1971), and from the observation that the respiration of nodule slices (Smith, 1949; Tjepkema, 1971) and isolated bacteroids (Bergersen, $1962 \mathrm{a}$; Tjepkema, 1971) is oxygen saturated at a much lower $\mathrm{pO}_{2}$ than is the respiration of whole nodules. It is very difficult to explain these findings except by postulating a large diffusion resistance between the bacteroids and the external atmosphere. Further evidence for diffusion limitation of oxygen uptake by nodules comes from the temperature dependence of respiration plotted versus $\mathrm{pO}_{2}$ as shown in Fig. 2. For respiratory enzymes, a $Q_{10}$ of two to three is observed (James, 1954), while for a diffusion process the $Q_{10}$ should be 1.15 (Wittenberg, 1970). Although these $\mathbf{Q}_{10}$ values are based on measurement of respiration rate at fixed $\mathrm{pO}_{2}$, they should also hold for the increase in respiration rate due to a given increase in $\mathrm{pO}_{2}$. From the original data for Fig. 2, for the linear portion of the curve, we have calculated the increase in respiration rate divided by the corresponding increase in $\mathrm{pO}_{2}$. At $23^{\circ}$, this was measured from 0.3 to $0.9 \mathrm{~atm}$, and at $13^{\circ}$ it was measured from 0.1 to $0.3 \mathrm{~atm}$. The ratio of these two numbers, the $\mathrm{Q}_{10}$, was 1.07 . This result strongly supports the hypothesis that a diffusion process is involved in this part of the respiration curve. It will be noted that in Fig. 2, respiration at $13^{\circ}$ reaches the point of oxygen saturation of respiration at $0.5 \mathrm{~atm}$, while at $23^{\circ}$ there is no indication of saturation, even at $0.9 \mathrm{~atm}$. This is because the maximum rate of respiration is determined by the maximum turnover rate of the respiratory enzymes, and this is strongly temperature dependent.

The third and final condition for fitting soybean nodule respiration to a diffusion-limited version of the Lommen et al. model is that the resistance to diffusion be about the same for all respiratory sites. The diffusion pathway of oxygen to the bacteroids appears to be first through 
the nodule cortex, then through the intercellular air spaces of the central tissue, and finally through the contents of the central cells to the bacteroids. Of these three components of the diffusion pathway, only the cortex will provide the same resistance to oxygen diffusion to all respiratory sites. Thus we can apply the model of Lommen et al. only if the cortex is responsible for most of the diffusion resistance to the bacteroids.

Tjepkema (1971) has studied this question by calculation. For the cortex, a calculation was made of the thickness of the cortex required if all of the resistance was at the cortex. Fick's law and the data of Fig. 2 were used. The calculation was based on diffusion through a liquid shell whose surface area was the same as that of the nodule, and it was assumed that the inside of the shell was at a negligible $\mathrm{pO}_{2}$ compared to the exterior $\mathrm{pO}_{2}$. The oxygen flux corresponding to a given $\mathrm{pO}_{2}$ gradient across the shell was calculated from the slope of the linear portion of the plot of respiration rate versus $\mathrm{pO}_{2}$ in Fig. 2 . The calculated cortical thickness was $80 \mu$, compared to a measured cortical thickness of $410 \mu$ for the nodule of Fig. 2. But note that Sprent (1972) reports that intercellular air spaces are found throughout the cortex, and presumably connect the external atmosphere and the intercellular air spaces of the central tissue. If this is so, even the full $410 \mu$ thickness of the cortex would not be sufficient to provide the total resistance to oxygen diffusion into the nodule. However, with the light microscope, we find that intercellular air spaces are lacking between some of the cells of the cortex, and we feel that resistance equivalent to a $80 \mu$ thick liquid layer may be present.

To determine if the intercellular air spaces of the central tissue, or the central tissue cells could be responsible for a major portion of the resistance to oxygen diffusion, Tjepkema (1971) made calculations based on Fick's law, the dimensions of the cells and air spaces, and the flux of oxygen into the nodule. These calculations showed that only a small fraction of the resistance could be due to these two components of the diffusion pathway. By elimination, this supports the conclusion that most of the resistance is at the cortex.

We also have experimental evidence (manuscript in preparation) that supports this conclusion. Measurements of $\mathrm{pO}_{2}$ within nodules by microelectrode show that there is a large $\mathrm{pO}_{2}$ gradient at the nodule cortex, and a low but uniform $\mathrm{pO}_{2}$ from the center to edge of the central tissue. Since the $\mathrm{pO}_{2}$ gradient is proportional to the resistance ( $\mathrm{Tjep}$ kema, 1971), this is direct evidence that most of the resistance is at the cortex.

If we accept the above conclusion, all of the qualitative conditions for the diffusion-limited version of the Lommen et al. (1971) model have been met. Now let us see if the model fits our respiration data quan- 


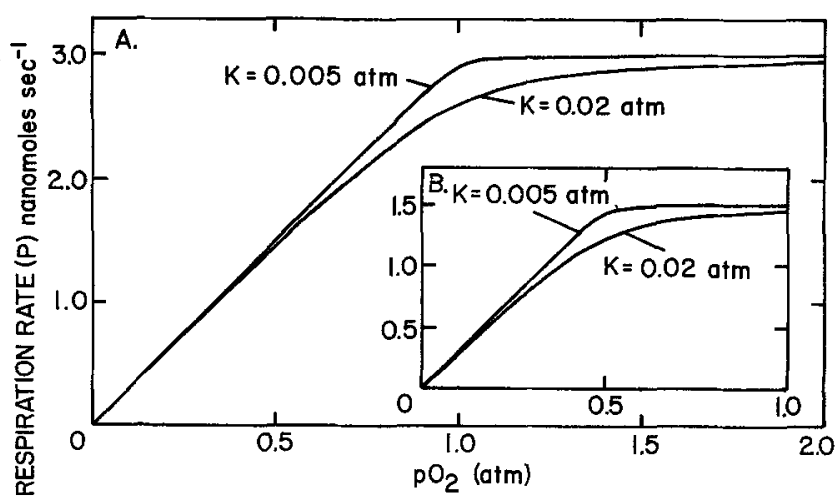

Fig. 7A and B. Soybean nodule respiration as represented by the model of Lommen et al. (1971). Respiration at $23^{\circ}$ is represented in Fig. $7 \mathrm{~A}$, while Fig. $7 \mathrm{~B}$ represents $13^{\circ}$. The value used for the resistance $(R)$ is $3.3 \times 10^{8} \mathrm{~atm} \mathrm{~s} \mathrm{~mol} \mathbf{m}^{-1}$ for both figures. For Fig. $7 \mathrm{~A}$, the maximum respiration rate $\left(\mathbf{P}_{\mathrm{M}}\right)$ is $3 \times 10^{-9} \mathrm{~mol} \mathrm{~s}-1$, while for Fig. $7 \mathrm{~B}$ it is $1.5 \times 10^{-9} \mathrm{~mol} \mathrm{~s}^{-1}$. The values given for $\mathrm{K}$ are equivalent to the Michaelis constant. The respiration rate and resistance are specific for a given nodule

titatively. For the symbols and the equation used by Lommen et al., their paper should be consulted. It should be noted that we have modified their units to ones more appropriate for soybean nodules. Rather than photosynthesis rate per unit of leaf area ( $\mathrm{P}$ of Lommen et al.), we have used respiration rate per nodule. Resistance is also in per nodule units, with atm $\mathrm{s} \mathrm{mol}^{-1}$ rather than $\mathrm{s} \mathrm{cm}^{-1}$.

Fig. $7 \mathrm{~A}$ approximates our results for nodule respiration at $23^{\circ}$. The saturated respiration rate, $\mathrm{P}_{\mathrm{M}}$ of Lommen et al., was calculated by multiplying the volume of the central tissue in Fig. 2 by $3 \times 10^{-8} \mathrm{~mol} \mathrm{~s}^{-1} \mathrm{~cm}^{-3}$. This is the value that Tjepkema (1971) found for the respiration rate per unit of central tissue volume. For Fig. 7B, which approximates nodule respiration at $13^{\circ}$, we used one-half of the above value for $P_{M}$. For both curves, the resistance value was calculated from the slope of the linear portion of data set 3, Fig. 2. For the calculation, we used the equation $R=\Delta \mathrm{pO}_{2} \Delta \mathrm{Q}^{-1}$ (Tjepkema, 1971), where $\Delta \mathrm{pO}_{2}$ is the $0.6 \mathrm{~atm} \mathrm{pO}_{2}$ increase between 0.3 and $0.9 \mathrm{~atm}$ in data set 3 , and $\Delta \mathrm{Q}$ is the corresponding increase in respiration rate. With regard to the symbol $\mathrm{K}$ used in the model of Lommen et al., it is the $\mathrm{K}_{\mathrm{m}}$ for the Michaelis-Menten equation of enzyme activity. For soybean nodules, we have used $\mathrm{K}$ as the value of the $\mathrm{pO}_{2}$ in the intercellular air spaces of the central tissue at which respiration of the central tissue is half-saturated. This is an approximation, but the results of Tjepkema (1971) for the respiration of central tissue slices versus $\mathrm{pO}_{2}$ do appear to be roughly described by the Michaelis-Menten equation. In Fig. 7, we have used 


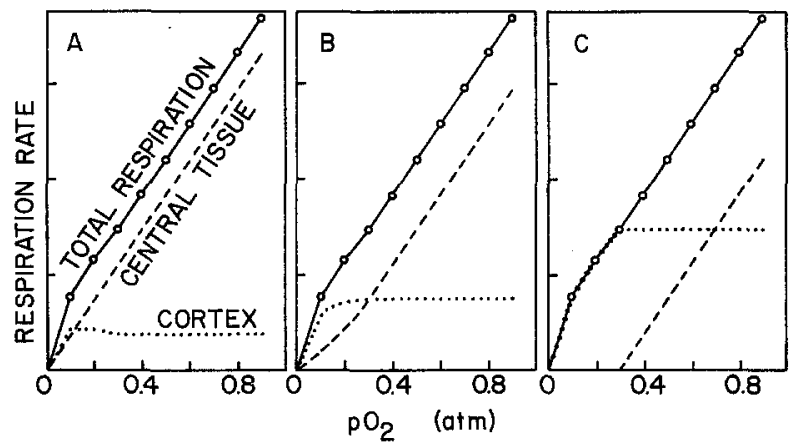

Fig. 8. Model curves for nodule respiration as the sum of cortex and central tissue respiration. Data set 3 of Fig. 2 was used for the total respiration rate

$K$ values of 0.001 and $0.02 \mathrm{~atm}$, which cover the range of values that we estimate for K. Now compare the model curves of Fig. 7 to the actual respiration curves of nodules given in Figs. 2 and 3. Except at low $\mathrm{pO}_{2}$ values, which we will discuss in the next section, the shapes agree closely. Thus it appears that the model of Lommen et al. fits our respiration data for the linear part of the plot of respiration rate versus $\mathrm{pO}_{2}$ and for the elbow in the curve at oxygen saturation.

\section{Initial Part of the Respiration Curve}

We propose that cortical respiration is the reason why the initial portion of the nodule respiration curve varies from the model of Lommen et al. (1971). Fig. 8 shows how total nodule respiration may be the sum of the cortex and central tissue respiration. Model A was drawn to show the minimum cortical respiration possible. Models $\mathrm{B}$ and $\mathrm{C}$ show how higher levels of cortical respiration are also possible.

Of these models, Model B is probably closest to reality. This is because the shape of the central tissue respiration curve in Model B is similar to the curve for acetylene reduction versus $\mathrm{pO}_{2}$ reported by Mague and Burris (1972). They reported a linear increase of acetylene reduction rate with increasing $\mathrm{pO}_{2}$, with a sharp elbow at the point of oxygen saturation. Bergersen (1970) and Koch and Evans (1966) have reported similar results for acetylene reduction rate versus $\mathrm{pO}_{2}$. It would appear that, as the external $\mathrm{pO}_{2}$ is increased, the increase in acetylene reduction rate is directly proportional to the increase in respiration rate of the central tissue. Thus the shape of the two curves would be identical.

Bergersen (1962a) has reported nodule respiration curves that were substantially different from ours, having an abrupt upward inflection 
in the curve at approximately $0.5 \mathrm{~atm}$ external $\mathrm{pO}_{2}$. We have no explanation for this difference, but it does not appear to be due to Bergersen's use of smaller nodules, since we obtained the same results with small nodules as we did with large nodules (Tjepkema, 1971).

\section{The Role of Leghemoglobin in Oxygen Diffusion}

There has been increased speculation that leghemoglobin facilitates oxygen diffusion in soybean nodules (Bergersen et al., 1973; Bergersen, 1971). There is also some experimental evidence for this hypothesis (Bergersen et al., 1973; Tjepkema, 1971). But Smith (1949) found that $\mathrm{CO}$, at a sufficient partial pressure to convert all of the nodule leghemoglobin to carboxyleghemoglobin, caused no inhibition of respiration. This experiment has been used as evidence against a role of leghemoglobin in oxygen transport. In the experiment shown in Fig. 6, we have confirmed the results of Smith, although at saturating $\mathrm{pO}_{2}$ values, there was a small inhibition by $\mathrm{CO}$. This was probably due to a direct inhibition of the respiratory enzymes.

The lack of a $\mathrm{CO}$ inhibition of respiration at non-saturating $\mathrm{pO}_{2}$ values does not prove that leghemoglobin has no effect on oxygen transport in the nodule. This is because the respiration rate of the central tissue of the nodule, where the leghemoglobin is located, appears to be controlled by the rate of oxygen diffusion through the cortex. Consider the following example: suppose that the $\mathrm{pO}_{2}$ of the intercellular air spaces of the central tissue was $1 \times 10^{-4} \mathrm{~atm}$ before carboxyleghemoglobin formation and $1 \times 10^{-2} \mathrm{~atm}$ afterwards. In spite of the 100 fold increase in $\mathrm{pO}_{2}$, there would be no measurable effect on oxygen diffusion through the nodule cortex. This is because the $\mathrm{pO}_{2}$ gradient across the cortex, which determines the rate of oxygen diffusion through the cortex, would change only slightly. It would be $0.2-1 \times 10^{-4} \mathrm{~atm}$ before carboxyleghemoglobin formation and $0.2-1 \times 10^{-2} \mathrm{~atm}$ afterwards. Thus leghemoglobin might greatly decrease the $\mathrm{pO}_{2}$ gradient in the central tissue cells, even though it has little effect on the total respiration rate of the nodule.

\section{Nodule $\mathrm{pO}_{2}$ and Nitrogen Fixation}

It appears that there is an optimum $\mathrm{pO}_{2}$ range for nitrogen fixation. by the bacteroids (Bergersen, 1971) and we propose that nodule structure helps to maintain this optimum $\mathrm{pO}_{2}$. We suggest that the diffusion resistance of the nodule cortex acts to reduce the central tissue $\mathrm{pO}_{2}$ to the general $\mathrm{pO}_{2}$ range that is optimal, while the low diffusion resistance of the intercellular air spaces of the central tissue acts to keep all of the central tissue cells at about the same $\mathrm{pO}_{2}$. For the individual central tissue cells, facilitation of oxygen diffusion by leghemoglobin may serve to keep the $\mathrm{pO}_{2}$ difference between the inner and outer bacteroids at a minimum. 
National Science Foundation and University of Michigan predoctoral fellowships are gratefully acknowledged by J. D. T.

\section{References}

Appleby, C. A.: Properties of leghemoglobin in vivo, and its isolation as ferrous oxyleghemoglobin. Biochim. biophys. Acta (Amst.) 188, 222-229 (1969)

Bergersen, F. J.: The effects of partial pressure of oxygen upon respiration and nitrogen fixation by soybean root nodules. J. gen. Microbiol. 29, 113-125 (1962a)

Bergersen, F. J.: Oxygenation of leghemoglobin in soybean root-nodules in relation to the external oxygen tension. Nature (Lond.) 194, 1059-1061 (1962 b)

Bergersen, F. J.: The quantitative relationship between nitrogen fixation and the acetylene-reduction assay. Aust. J. biol. Sci. 23, 1015-1025 (1970)

Bergersen, F. J.: Biochemistry of symbiotic nitrogen fixation in legumes. Amn. Rev. Plant Physiol. 22, 121-140 (1971)

Bergersen, F. J., Turner, G. L., Appleby, C. A.: Studies of the physiological role of leghemoglobin in soybean root nodules. Biochim. biophys. Acta (Amst.) 292, 271-282 (1973)

Blackman, F. F., Smith, A. M.; Experimental researches on vegetable assimilation and respiration. IX. On assimilation in submerged water-plants and its relation to the concentration of carbon dioxide and other factors. Proc. roy. Soc. B $83,389-412$ (1911)

Bond, G.: Symbiosis of leguminous plants and nodule bacteria. I. Observations on respiration and on the extent of utilization of host carbohydrates by the nodule bacteria. Ann. Bot., N.S. 5, 313-337 (1941)

Goddard, D. R., Bonner, W. D.: Cellular respiration. In: Plant physiology, a treatise, vol. IA, p. 209-312, Steward, F. C., ed. New York: Academic Press 1960

James, W. O.: Plant respiration. London: Oxford Univ. Press 1953

Kirk, P. L.: Quantitative ultramicroanalysis. New York: Wiley 1950

Koch, B., Evans, H. J.: Reduction of acetylene to ethylene by soybean root nodules. Plant Physiol. 41, 1748-1750 (1966)

Lommen, P. W., Schwintzer, C. R., Yocum, C. S., Gates, D. M.: A model describing photosynthesis in terms of gas diffusion and enzyme kinetics. Planta (Berl.) 98, 195-220 (1971)

Mague, T. H., Burris, R.H.: Reduction of acetylene and nitrogen by field-grown soybeans. New Phytologist 71, 275-286 (1972)

Smith, J. D.: Haemoglobin and the oxygen uptake of leguminous root nodules. Biochem. J. 44, 591-598 (1949)

Sprent, J. I.: Prolonged reduction of acetylene by detached soybean nodules. Planta (Berl.) 88, 372-375 (1969)

Sprent, J. I.: The effeets of water stress on nitrogen-fixing root nodules. II. Effects on the fine structure of detached soybean nodules. New Phytologist 71, 443-450 (1972)

Thimann, K. V., Yocum, C. S., Hackett, D. P.: Terminal oxidase and growth in plant tissues. III. Terminal oxidation in potato tuber tissue. Arch. Biochem. Biophys. ð33, 239-257 (1954)

Tjepkema, J. D.: Oxygen transport in the soybean nodule and the function of leghemoglobin. Doct. dissert. Univ, of Michigan, Ann Arbor, Mich., USA 1971

Wittenberg, J. B.: Myoglobin-facilitated oxygen diffusion: role of myoglobin in oxygen entry into muscle. Physiol. Rev. 50, 559-636 (1970) 